\title{
Changes in serum hepcidin according to thyrometabolic status in patients with Graves' disease
}

\author{
Aleksandra Krygier, Ewelina Szczepanek-Parulska, Dorota Filipowicz and Marek Ruchała \\ Department of Endocrinology, Metabolism and Internal Medicine, Poznan University of Medical Sciences, Poznan, Poland
}

Correspondence should be addressed to E Szczepanek-Parulska: ewelinaparulska@gmail.com

\begin{abstract}
Introduction: Hepcidin is an acute-phase protein and a key regulator of iron homeostasis. Anaemia frequently occurs in patients with thyroid dysfunction, and hepcidin may be a potential link.

Objectives: Prospective assessment of hepcidin serum concentration and other parameters related to Fe homeostasis in hyperthyroid patients in the course of GD at diagnosis and during remission.

Patients and Methods: Out of the 70 patients recruited, 42 (32 women, 10 men), aged

$42.5 \pm 15.1$ years, met the inclusion criteria. Clinical and biochemical assessment, including hepcidin measurement by ELISA, was performed at baseline (TO) and after restoration of euthyroidism (T1).

Results: Hepcidin concentration at T0 in the 24 patients who completed the study was significantly higher than the value during euthyroidism $(28.7$ (8.1-39.4) ng/mL vs 7.9 (4.3-12.9) ng/mL, $P<0.001)$. Hepcidin level was most significantly correlated with ferritin (rho $=0.723$ ) in women at T0. In both men (377 (171-411) vs 165 (84-237) ng/mL, $P=0.001)$ and women (84 (23-104) vs $35(16-64) \mathrm{ng} / \mathrm{mL}, P=0.001)$, a significant decrease in ferritin level was demonstrated following therapy. A significant $(P<0.001)$ increase in mean corpuscular volume (MCV) (83.5 (82.5-87.1) vs 89.5 (88.8-90.0) fL) and mean concentration of haemoglobin (MCH) (29.0 (28.0-29.4) vs 30.4 (29.5-31.1) pg)

was observed.

Conclusions: Hepcidin and ferritin decrease significantly during the transition from a hyperthyroid state to euthyroidism in patients with GD. The observed changes occur in parallel to iron homeostasis fluctuations. During the transition from the hyperthyroid state to euthyroidism, the improvement of haematological status is reflected mainly by the increase in MCV and $\mathrm{MCH}$.
\end{abstract}

Key Words

- hepcidin

- Graves' disease

- hyperthyroidism

- anaemia

- iron

\section{Introduction}

In the biochemical landscape of thyroid dysfunction, iron (Fe) homeostasis abnormalities are frequently observed (1, 2 ). The prevalence of anaemia in overt hyperthyroidism was found to be higher (14.6\%) than in overt hypothyroidism $(7.7 \%)$, subclinical thyroid dysfunctions (3.3-5\%) and the euthyroid state (4.7\%) according to a large cohort study (3). Notably, reports indicated that complete blood count (CBC) disturbances commonly resolve after restoration of euthyroidism (4).

The mechanism responsible for anaemia in the course of hyperthyroidism is not well understood. Due to accelerated metabolism and thus higher oxygen https://ec.bioscientifica.com

https://doi.org/10.1530/EC-20-0017

C 2020 The authors Published by Bioscientifica Ltd

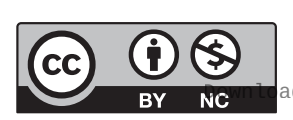

This work is licensed under a Creative Commons Attribution-NonCommercial 4.0 International License. ded from Bioscientifica.com at 04/26/2023 01:24:30PM 
requirements, bone marrow presents erythroid hyperplasia, where ineffective erythropoiesis occurs. Consequently, Fe utilization is inappropriate (5). Typically, microcytic anaemia is the most representative form of thyroid hormone excess $(6,7)$. In a group of 235 hyperthyroid patients, microcytic anaemia was detected in 30.3\%, while isolated microcytosis (decreased MCV with normal haemoglobin) was detected in $57.4 \%$ of patients (4). The most common cause of hyperthyroidism is autoimmune Graves' disease (GD). Immunologic factors, acting via inflammatory markers, might be an additional underlying cause of haematologic changes in GD, next to the thyroid hormone excess (8).

Hepcidin is a liver-derived protein responsive to $\mathrm{Fe}$ plasma concentration and helps maintain proper iron status. It acts mainly through blockage of Fe transporters in the duodenum. Another pathway leading to hepcidin overexpression is triggered by inflammation, particularly interleukin-6 (IL-6) (9). Thus, both mechanisms may play a role in anaemia under thyroid hormonal disturbances. We have already demonstrated that the hepcidin serum level is high at the diagnosis of other thyroid inflammatory diseases, subacute thyroiditis (SAT) and Hashimoto's thyroiditis and significantly decreases after treatment. The observed changes in hepcidin concentration take place along with the improvement of iron homeostasis parameters $(10,11)$. So far, data concerning the role of hepcidin in hyperthyroidism are sparse and ambiguous, which might be related to the diverse aetiology and severity of thyroid disease among the studied participants $(12,13)$. Thus, the aim of our study was to prospectively assess hepcidin serum concentration and other parameters related to Fe homeostasis in a well-characterized group of hyperthyroid patients exclusively in the course of GD at diagnosis and during remission.

\section{Patients and methods}

The research was conducted in accordance with the declaration of Helsinki and was approved by the Poznan University of Sciences Bioethics Committee (approval number: 386/16). All patients agreed to participate in the study by signing written informed consent.

\section{Study design}

The project was carried out in an outpatient clinic at the tertiary reference endocrine centre. This was a prospective observational study on hyperthyroid patients with GD.
The evaluation of patients was conducted twice: at the moment of diagnosis (T0) in the hyperthyroid state and after euthyroidism was restored (T1). Each time, the patients were physically examined. Then, laboratory tests (including hepcidin measurement) and thyroid ultrasound examination were performed. Following the initial evaluation (T0), patients were treated with thiamazole. The initial dose was $40 \mathrm{mg}$ or $60 \mathrm{mg}$ per day (depending on the severity of the disease), and the dose was gradually tapered under the systematic control of TSH and free thyroid hormone levels every 4-8 weeks. Liver aminotransferases and complete blood count were additionally controlled when side effects in the form of liver failure or granulocytopenia were suspected. The state of remission was defined as a lack of clinical symptoms of hyperthyroidism, accompanied by full normalization of TSH and free thyroid hormones without anti-thyroid therapy or with the use of a low maintenance dose of $2.5 \mathrm{mg}$ of thiamazole per day.

\section{Studied group}

The studied group included adult patients with a confirmed newly diagnosed first episode of hyperthyroidism in the course of GD.

\section{Assessment of patients}

The diagnosis of GD hyperthyroidism (constituting the inclusion criterium) was based on clinical, laboratory (significant elevation of free thyroid hormones, decreased thyroid-stimulating hormone and positive antithyrotropin receptor autoantibodies) and sonographic (decreased inhomogeneous echogenicity and increased vascularization) features (Fig. 1). To avoid the influence of other (than thyroid disease) factors on hepcidin level, several exclusion criteria were strictly respected (Fig. 2). Patients with a positive personal history of previous episodes of hyperthyroidism were also excluded from the analysis. Moreover, to ensure homogeneity of the group, patients with thyrotoxicosis of an aetiology other than GD were also excluded. Blood was always collected in the morning after at least $8 \mathrm{~h}$ of fasting.

The level of hepcidin was measured by the Hepcidin 25 (bioactive) hs ELISA, a highly sensitive enzyme immunoassay for the quantitative in vitro diagnostic measurement (DRG Instruments GmbH, Germany). The thyroid gland status was characterized by thyroidstimulating hormone (TSH), free thyroid hormones (free triiodothyronine - fT3 and free thyroxine - fT4) and autoantibodies (anti-thyroid peroxidase - TPOAb,

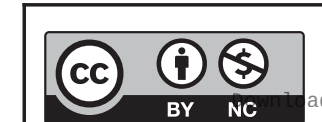




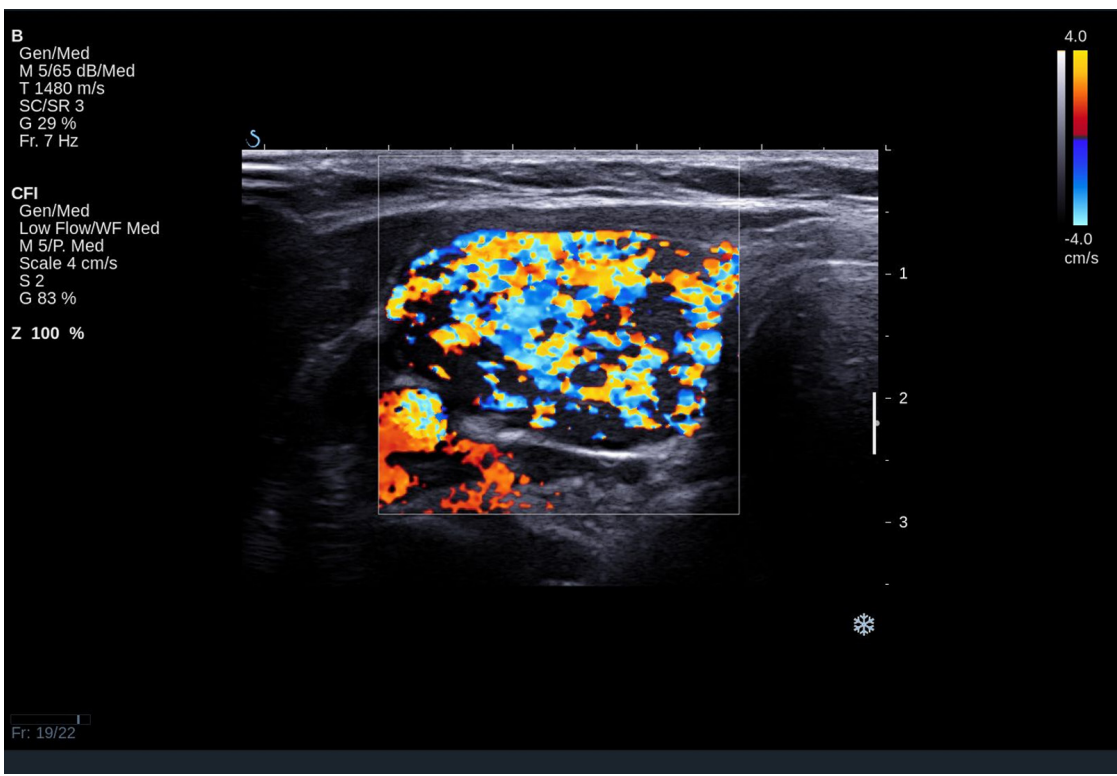

\section{Figure 1}

An ultrasound picture presenting one of the patients at diagnosis of hyperthyroidism in the course of Graves' disease, demonstrating decreased echogenicity of the thyroid parenchyma and significantly increased blood flow visualized by colour Doppler examination.

anti-thyroglobulin - TGAb and anti-TSH receptor TRAb). To exclude chronic liver and kidney failure or acute inflammatory states, the following parameters were also measured: alanine aminotransferase (ALT), aspartate aminotransferase (AST), creatinine with eGFR (estimated glomerular filtration rate) and C-reactive protein (CRP). The ferritin level, Fe and complete blood count (CBC) were used to evaluate iron homeostasis.

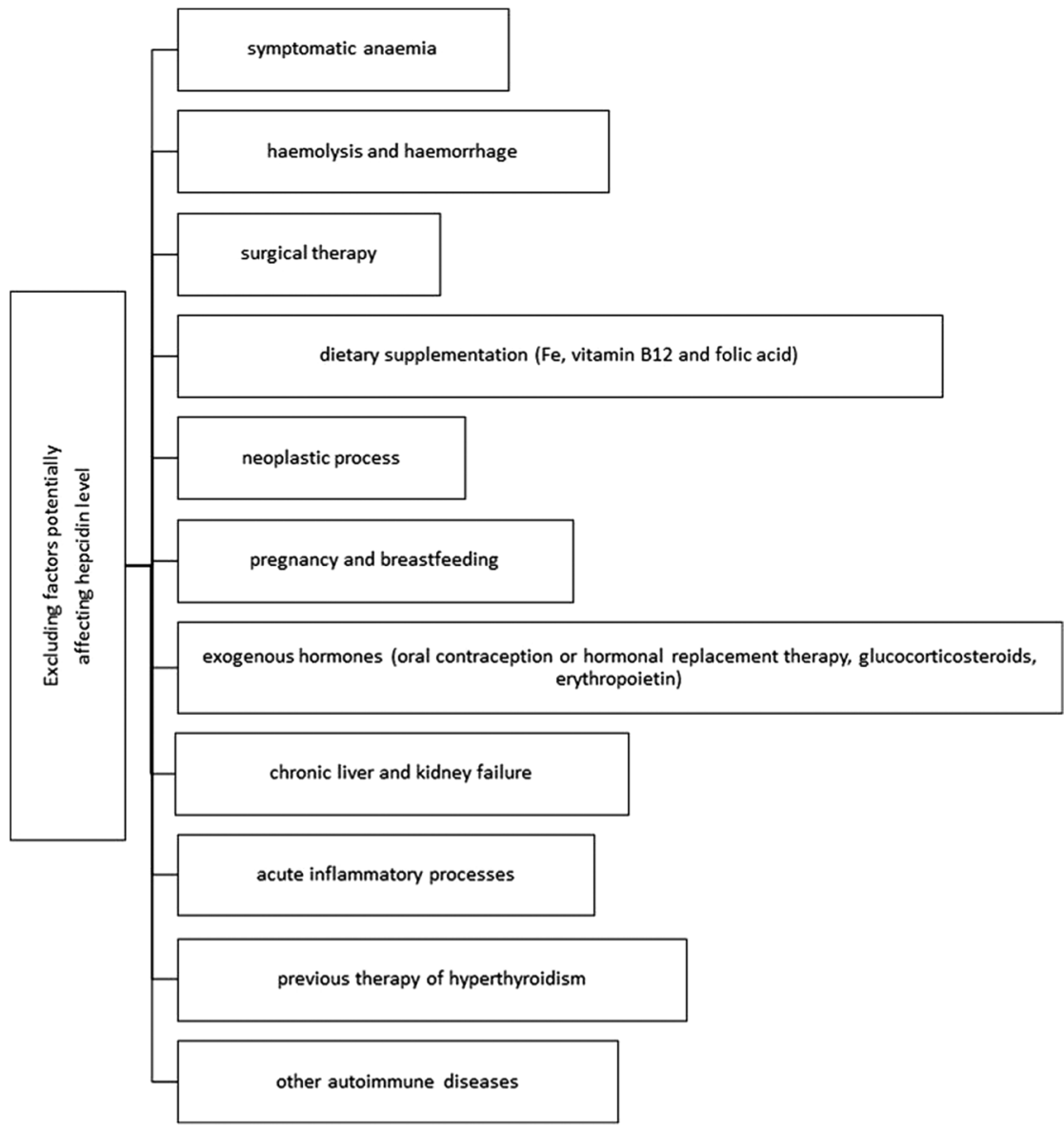

Figure 2

Factors affecting hepcidin level, constituting the exclusion criteria of our study. https://ec.bioscientifica.com https://doi.org/10.1530/EC-20-0017 (c) 2020 The authors Published by Bioscientifica Ltd
This work is licensed under a Creative Commons Attribution-NonCommercial 4.0 International License. ded from Bioscientifica.com at 04/26/2023 01:24:30PM 
The assessment of ALT, AST, Fe, creatinine and CRP was performed using a Hitachi Cobas e501 analyser (Roche Diagnostics), while the measurements of thyroid-related parameters (TSH, fT3, fT4, TPOAb and TGAb) and ferritin were done using a Hitachi Cobas e601 chemiluminescent analyser (Roche Diagnostics). The eGFR was estimated by an online medical calculator (https://www.mdcalc.com/ mdrd-gfr-equation) based on the MDRD (Modification of Diet in Renal Disease Study) equation. The CBC was measured by an automated flow cytometer Sysmex-XN 1000 (Sysmex Europe GmbH, Born-barch, Germany). An AIXPLORER system (Supersonic Imagine, Aix en-Provence, France) was used for ultrasound examination of the thyroid gland.

\section{Statistical methods}

The acquired data were analysed statistically using STATISTICA software (StatSoft, Tulsa, Oklahoma, USA). Non-parametric tests were applied. The Wilcoxon signedrank test was used to compare two related samples (T0 vs T1). Spearman's rank correlation coefficient was used to evaluate the correlation between hepcidin and other laboratory parameters before recovery (T0). The data are presented as median and 25-75\% interquartile range (IQR). The parameters with different reference ranges in men and women were calculated separately. The level of statistical significance was set at $P<0.05$.

\section{Results}

Seventy patients with suspicion of hyperthyroidism in the course of GD were screened for eligibility criteria. In the end, 42 patients met the inclusion criteria, were enrolled in the study and underwent initial assessment (T0). The mean age of patients who qualified for analysis was $42.5 \pm 15.1$ years (range 18-70), median 38 (IQR 30-50). Twenty-four patients were also assessed for a second time, after complete remission was achieved (T1), while 18 did not fulfil the remission criteria or were lost to follow-up. The time range to achieve euthyroidism (from T0 to T1) was 6 to 24 months from diagnosis.

\section{Hepcidin}

The median hepcidin concentration at $\mathrm{T} 0$ in 42 patients was $13.7(5.6-38.4) \mathrm{ng} / \mathrm{mL}$, whereas in men it reached
$50.2(33.5-66.0) \mathrm{ng} / \mathrm{mL}(n=10)$ and in women it reached $8.4(2.3-19.1) \mathrm{ng} / \mathrm{mL}(n=32)$.

The level of hepcidin was correlated with all biochemical parameters measured in this study before treatment (T0) in the whole studied group and in females only for parameters with different reference ranges depending on sex. The most statistically significant correlation was observed for hepcidin and ferritin $(\mathrm{rho}=0.723)$ in women at T0, denoted in Fig. 3.

In 24 patients who achieved remission of the disease, the concentration of hepcidin at diagnosis of GD was compared to the level of hepcidin in remission (T0 vs T1). The data are presented in Table 1. Additional calculations were performed separately in the female and male subgroups (Table 2). A statistically significant decrease in hepcidin and ferritin concentrations was observed in men and women (Fig. 4).

\section{Other parameters}

Analysis of 24 patients who were evaluated both before (T0) and after therapy (T1) revealed that, at T1, patients presented a statistically significant improvement in thyroid status, reflected by normalisation of all parameters (TSH, fT3 and fT4) and reductions in the concentration of autoantibodies (TPOAb, TGAb and TRAb). The parameters of $\mathrm{CBC}$ not dependent on sex, such as MCV and MCH, were significantly higher following treatment when compared to values at diagnosis (Table 1). The level of CRP (1.1 (0.5-2.9) vs $1.2(0.6-1.7) \mathrm{mg} / \mathrm{L})$ did not change significantly during therapy.

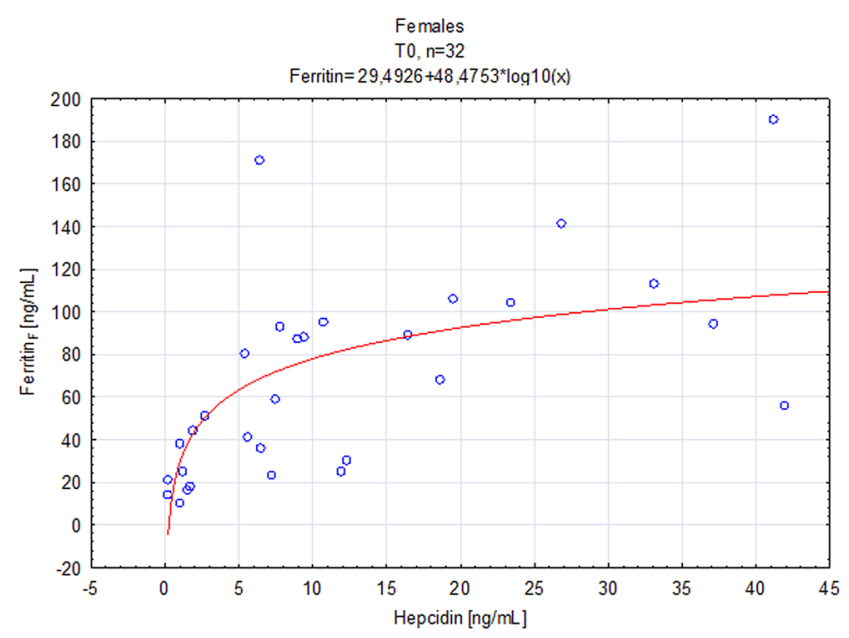

Figure 3

Correlation of hepcidin and ferritin in the women at baseline (TO). The non-parametric Spearman test was used, and the result is presented as a logarithmic scale $(\mathrm{rho}=0.723)$.

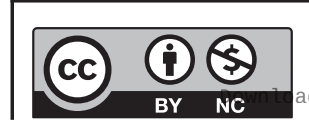


Table 1 Biochemical parameters in patients with hyperthyroidism due to Graves' disease (GD) at baseline (T0) compared to the values obtained following complete remission of the disease (T1).

\begin{tabular}{l}
\hline Parameter \\
\hline Hepcidin $(\mathrm{ng} / \mathrm{mL})$ \\
WBC $\times 10^{3} / \mu \mathrm{l}$ \\
MCV $(\mathrm{fL})$ \\
MCH $(\mathrm{pg})$ \\
MCHC $(\mathrm{g} / \mathrm{dL})$ \\
RDW-CV $(\%)$ \\
PLT $\times 10^{3} / \mu \mathrm{l}$ \\
TSH $(\mu \mathrm{IU} / \mathrm{mL})$ \\
fT3 $(\mathrm{pmol} / \mathrm{L})$ \\
fT4 $(\mathrm{pmol} / \mathrm{L})$ \\
TPOAb $(\mathrm{IU} / \mathrm{mL})$ \\
TGAb $(\mathrm{IU} / \mathrm{mL})$ \\
TRAb $(\mathrm{IU} / \mathrm{L})$
\end{tabular}

\begin{tabular}{c}
\hline Reference range \\
\hline $\mathbf{0 . 2}-47.7$ \\
$3.9-11.0$ \\
$\mathbf{8 0 . 0}-99.0$ \\
$\mathbf{2 7 . 0}-33.5$ \\
$31-38$ \\
$11.0-16.0$ \\
$130-400$ \\
$\mathbf{0 . 2}-4.2$ \\
$3.9-6.7$ \\
$\mathbf{1 1 . 5 - 2 1 . 0}$ \\
$<34$ \\
$\mathbf{1 0 - 1 1 5}$ \\
$<2$
\end{tabular}

\begin{tabular}{c}
\hline GD $($ TO $n=24$ \\
\hline $28.7(8.1-39.4)$ \\
$7.1(5.9-8.6)$ \\
$83.5(82.5-87.1)$ \\
$29.0(28.0-29.4)$ \\
$34(33-34)$ \\
$12.6(11.9-13.3)$ \\
$266(237-301)$ \\
$0.01(0.01-0.01)$ \\
$14.8(9.4-29.0)$ \\
$37.3(27.8-61.8)$ \\
$117(13-227)$ \\
$60(11-594)$ \\
$6(2-11)$
\end{tabular}

\begin{tabular}{c}
\hline GD $(T 1) n=24$ \\
$7.9(4.3-12.9)$ \\
$6.9(6.0-8.0)$ \\
$89.5(88.8-90.0)$ \\
$30.4(29.5-31.1)$ \\
$34(33-34)$ \\
$12.8(12.5-13.1)$ \\
$254(229-289)$ \\
$1.0(0.6-2.0)$ \\
$4.7(4.5-5.2)$ \\
$15.9(14.7-17.1)$ \\
$46(17-139)$ \\
$20(10-248)$ \\
$1(1-3)$
\end{tabular}

\begin{tabular}{c}
\hline P-value \\
\hline$<0.001$ \\
$N S$ \\
$<0.001$ \\
$<0.001$ \\
$N S$ \\
$N S$ \\
$N S$ \\
$<0.001$ \\
$<0.001$ \\
$<0.001$ \\
0.01 \\
0.01 \\
$<0.001$
\end{tabular}

Values are expressed as median (IQR) for the nonparametric Wilcoxon signed-rank test.

fT3, free triiodothyronine; fT4, free thyroxine; MCH, mean corpuscular haemoglobin; MCHC, mean corpuscular haemoglobin concentration; MCV, mean corpuscular volume; $n$, number of patients; NS, non-significant; PLT, platelets; RDW-CV, red blood cell distribution width-coefficient of variation; TGAb, anti-thyroglobulin antibodies; TPOAb, anti-thyroid peroxidase antibodies; TRAb, thyrotropin receptor antibodies; TSH, thyroid-stimulating hormone; WBC, white blood cells.

Additional analysis was performed for the two subgroups divided according to sex. Altogether, 18 women completed the full treatment trial. Among the parameters with different reference ranges depending on sex, RBC and ferritin became significantly lower following remission than at baseline (Table 2).

Statistically significant differences in biochemical parameters in the male patients $(n=6)$ who were observed until complete remission of the disease was achieved are presented in Table 2 .

\section{Discussion}

Hepcidin, presumed to be a potential link in the mutual relationship between thyrometabolic and haematologic status, is a liver-derived protein encoded by the HAMP gene, responsible mainly for bodily Fe distribution (9). The mechanism of hepcidin response to inflammatory stimuli comprises two possible pathways: one through bone morphogenetic protein-mothers against decapentaplegic (BMP-SMAD) and more specifically via Janus kinase (JAK) signal transducer and activator of transcription 3 (STAT3). The latter axis is triggered by cytokines, mainly IL-6, which activates JAK2 and leads to phosphorylation of STAT3, enabling its translocation to the nucleus and upregulation of HAMP gene transcription. IL-6 also contributes to hepcidin regulation via the BMD pathway (14). Cross-talk between two presented pathways has been postulated (15). Stimulated hepcidin affects ferroportin, which is a cellular iron transporter, causing its internalization and degradation, thus retaining $\mathrm{Fe}$ absorption from a lumen of duodenum, macrophages of the liver and spleen as well as hepatocytes into plasma (16).

Table 2 Iron-related parameters significantly changed in patients with Graves' disease (GD) after the transition from hyperthyroidism (T0) to euthyroidism (T1), according to sex.

\begin{tabular}{|c|c|c|c|c|}
\hline Parameter & Hepcidin (ng/mL) & $\mathrm{RBC} \times 10^{6} / \mu \mathrm{l}$ & Ferritin (ng/mL) & Fe $(\mu g / d L)$ \\
\hline Reference range & $0.2-47.7$ & $\begin{array}{l}F: 3.5-5.2 \\
M: 4.2-5.8\end{array}$ & $\begin{array}{l}F: 13-150 \\
M: 30-400\end{array}$ & $\begin{array}{l}F: 37-145 \\
M: 59-158\end{array}$ \\
\hline $\mathrm{GD}_{\mathrm{F}}(\mathrm{T} 0) n=18$ & $10.0(1.7-33.1)$ & $4.7(4.5-5.0)$ & $84(23-104)$ & $119(79-145)$ \\
\hline $\mathrm{GD}_{\mathrm{F}}(\mathrm{T} 1) n=18$ & $5.0(1.6-10.2)$ & $4.5(4.3-4.7)$ & 35 (16-64) & 103 (78-138) \\
\hline $\mathrm{p}_{\mathrm{F}}$ value & 0.003 & 0.003 & 0.001 & NS \\
\hline $\mathrm{GD}_{\mathrm{M}}(\mathrm{TO}) n=6$ & 41.6 (33.5-60.1) & $5.2(4.6-5.6)$ & 377 (171-411) & 125 (104-132) \\
\hline $\mathrm{GD}_{\mathrm{M}}(\mathrm{T} 1) n=6$ & $10.0(8.4-14.0)$ & $4.7(4.7-5.1)$ & 165 (84-237) & 89 (62-108) \\
\hline $\mathrm{p}_{\mathrm{M}}$-value & 0.03 & NS & 0.04 & 0.04 \\
\hline
\end{tabular}

Values are expressed as median (IQR) for the nonparametric Wilcoxon signed-rank test.

F - females; Fe - iron; M - males; $n$ - number of patients; NS - non-significant; RBC - red blood cells.

https://ec.bioscientifica.com

https://doi.org/10.1530/EC-20-0017 (c) 2020 The authors Published by Bioscientifica Ltd

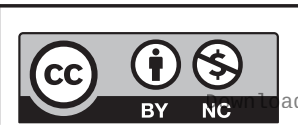

This work is licensed under a Creative Commons Attribution-NonCommercial 4.0 International License. ded from Bioscientifica.com at 04/26/2023 01:24:30PM 

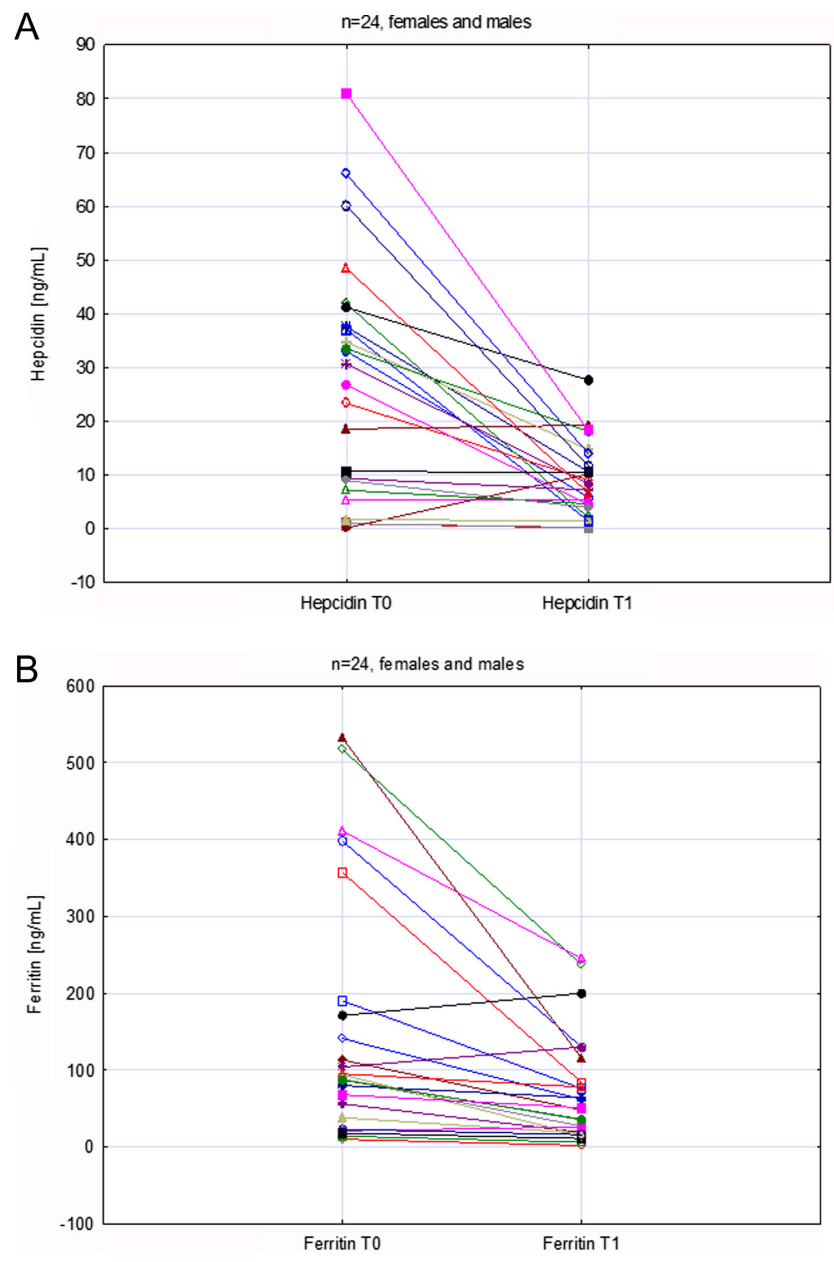

Figure 4

Changes in hepcidin and ferritin concentrations during the transition from hyperthyroidism (T0) to euthyroidism (T1).

Consequently, chronically increased hepcidin may lead to hypoferremia and iron-restricted anaemia, as in the pathogenesis of iron-refractory iron deficiency anaemia (IRIDA) (17). In contrast, hepcidin is inhibited by states characterized by increased erythropoiesis demand (anaemia, haemorrhage, haemolysis, hypoxia and $\beta$-thalassemia). Hepcidin's mechanisms of action are considered to be attractive therapeutic targets, with several agents under study during clinical trials (18).

Notably, IL-6 was markedly $(P<0.0001)$ elevated in the hyperthyroid population with GD and dropped significantly after methimazole therapy (19). Moreover, a positive correlation was found between fT3 and IL- 6 $(r=0.35, P<0.025)$ as well as between TRAb and IL-6 $(r=0.5$, $P<0.003$ ) (20). Additionally, polymorphisms in the IL-6 gene were found to be correlated with GD predisposition (21). It may be presumed that IL-6 overproduction in patients with GD stimulates the JAK2-STAT3 pathway to synthesize hepcidin, which consequently affects iron homeostasis and haematological parameters $(12,22)$.

Although very severe anaemia is not a common comorbidity in thyroid disorders, a better understanding of the mechanisms involved in iron homeostasis disturbances accompanying the hyperthyroid state and its restoration following antithyroid therapy may help to avoid unnecessary diagnostic procedures and supplementation (23). In view of the autoimmune background of GD and the frequent association of hyperthyroidism with haematological disturbances, we decided to evaluate the impact of thyroid function on hepcidin. To the best of our knowledge, this is the first study evaluating hepcidin concentration in a well-characterized, homogeneous group and the largest initially enrolled (42 patients) group so far, including the most representative female population with GD hyperthyroidism. The application of very strict inclusion and exclusion criteria allowed us to demonstrate for the first time that, in contrast to the foregoing attempts, a significant decrease in serum hepcidin was achieved (measured by the highly sensitive ELISA method) in patients with GD hyperthyroidism occurring after euthyroidism. The median hepcidin concentration was markedly lower after therapy, both in the whole group and in the male and female subgroups.

According to Fischli et al., fT3 stimulates hepcidin mRNA expression in vitro in a cell culture model (HepG2 cells) (12), but there has been no in vivo trial on proteins confirming the influence of thyroid hormones on hepcidin regulation at the pre- or posttranscriptional level. However, in our previous reports, we found positive correlations between hepcidin and fT3 in other thyroid inflammatory diseases, for example, Hashimoto's thyroiditis $(r=0.465, P=0.033)$ and SAT $(r=0.815, P<0.001)$ $(10,11)$. Presumably, the extent of fT3 disturbances in a course of GD hyperthyroidism is too high to reveal such a relationship. In the study by Fischli et al., no significant differences were noted in hepcidin concentration between hyper- and euthyroid states in patients with GD using the same method as in our study. The hepcidin level was markedly lower after recovery in males $(P<0.001)$, but not in females $(P=0.258)$, as measured by mass spectrometry (MS), a different method than in our study (12). In the whole group, a tendency for hepcidin measured using the ELISA method to decrease after treatment was noticeable $(n=25$; before $185 \mathrm{vs}$ after $115 \mathrm{ng} / \mathrm{mL}$ ); however, it did not reach statistical significance $(P=0.533)$. In another study by Lehtihet et al., hepcidin measured by ELISA did not change significantly during the transition from hyperthyroidism to the euthyroid state; however, a tendency for hepcidin

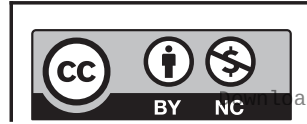

This work is licensed under a Creative Commons Attribution-NonCommercial 4.0 International License. ded from Bioscientifica.com at 04/26/2023 01:24:30PM 
to drop after treatment ( $7.52 \mathrm{vs} 5.47 \mathrm{ng} / \mathrm{mL}$ ) was noted (13). Although MS is considered a model method for hepcidin-25 measurements, hs ELISA has the advantages of simplicity, low cost, higher throughput and modest expenditure of labour, which makes it more suitable for implementation in clinical practice, as described before (24). Additionally, a strength of our study is a strict inclusion criteria, helping us include only patients with their first episode of GD hyperthyroidism, which allowed us to maintain homogeneity of the group.

Wefoundastrongpositivecorrelationbetweenhepcidin and ferritin at T0 in the female subgroup, confirming the association between hepcidin and iron status. Moreover, like hepcidin, the median ferritin significantly decreased after treatment. Presumably, the male group size was too small to achieve similar observations. This is consistent with previous research, where ferritin concentration was increased in hyperthyroid subjects and returned to the normal range after antithyroid therapy (25). The authors suggested that the increase in serum ferritin level in hyperthyroidism may be explained by the direct action of thyroid hormones on its synthesis or accompanying impaired iron utilization.

Although, among the included patients there was no diagnosed severe anaemia (exclusion criterium), and hence, the extent of disturbances might be too subtle to yield statistically significant differences. We noticed significant improvement of $\mathrm{MCV}$ and $\mathrm{MCH}$ in all patients. Although previous studies have shown a correlation between RDW and thyroid status reflected by a significant increase in RDW in the hypothyroid state, we failed to find a noticeable fluctuations of RDW during the transition from hyperthyroidism to euthyroid state (26, 27). The study by Gianoukakis et al. reported correction of anaemia of unknown origin in $89 \%$ of hyperthyroid patients due to GD following antithyroid therapy and in none with anaemia of other than hyperthyroidismrelated causes (8).

The mechanism of anaemia in hyperthyroidism is still uncertain. Thyroid hormones increase the basal metabolic rate, which results in higher oxygen demand and the need for oxygen transporters. Thyroid hormones induce erythropoiesis by acting directly on bone marrow, causing erythroid-line hyperplasia, and indirectly by erythropoietin (EPO) production through enhancing EPO gene expression (28). However, the boosted erythropoiesis may be ineffective, so pathological sideroblasts are visible in the marrow, and Fe utilization is diminished. Additionally, thyroid hormones were found to increase the 2,3-diphosphoglycerate concentration in RBCs, which facilitates oxygen delivery to tissues (29). This results in decreased MCV and MCH values. Moreover, enhanced erythrocyte osmotic fragility and oxidative stress lead to precocious haemolysis (30). Thus, although total red cell mass is increased in thyrotoxic patients, HGB and HTC are usually low due to a concomitant increase in plasma volume (5).

Although hepcidin is an acute inflammatory reactant, we did not find a positive correlation between this protein and CRP, as previously demonstrated in the case of SAT (10). This might be explained by the fact that GD is not an acute inflammatory process but rather a chronic autoimmune disease and is not associated with a significant increase in CRP concentration (31).

In our group, a sex difference in hepcidin concentration, as with ferritin, was observed. A higher hepcidin concentration was observed at T0 in males compared to females. Yang et al. found that 17- $\beta$-oestradiol suppressed hepcidin gene (HAMP) expression in vitro in human cells and therefore increased Fe uptake (32). This finding was confirmed by Lehtihet et al. during in vivo studies, where exogenous oestrogen administration caused a decrease of $40 \%$ in hepcidin- 25 in females (13). This phenomenon might at least partially explain our observation. Moreover, we noticed a wide range of hepcidin concentrations in particular subjects. According to Galesloot et al., the hepcidin concentration depends on the oestrogen status of the females, being the lowest in young women and higher following menopause, but independent of age in men (33). This may create potential limitations in comparisons of the studied females with the control group of healthy subjects, as the hepcidin concentration might depend on whether they are pre- or postmenopausal. In our study, most patients from the female subgroup were of premenopausal age with regular menstrual bleeding. Other limitations of the study should be noted here. The most relevant issue is the limited number of subjects who reached the T1 timepoint $(n=24)$ and the overall small male cohort $(n=10)$. Another is the method of hepcidin concentration assessment (ELISA), which is considered to present lower accuracy than MS. So far, measuring hepcidin-25 by LC-MS has been considered a gold standard. However, the comparison of this method with hs ELISA revealed a strong correlation between the results $(r=0.98 ; P<0.001)$, demonstrating the reliability of the results and high specificity of the autoantibodies used in hs ELISA to bind almost entirely to the bioactive form of hepcidin (24).

In conclusion, hepcidin level decreases significantly during the transition from the hyperthyroid state

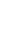

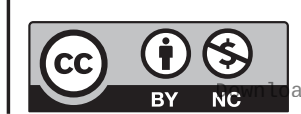

This work is licensed under a Creative Commons Attribution-NonCommercial 4.0 International License. ded from Bioscientifica.com at 04/26/2023 01:24:30PM 
to euthyroidism in patients with GD. The observed changes presumably occur in parallel to iron homeostasis fluctuation, especially a ferritin level decrease. During the transition from the hyperthyroid state to euthyroidism, the improvement of haematological status is reflected mainly by an increase in $\mathrm{MCV}$ and $\mathrm{MCH}$.

\section{Declaration of interest}

The authors declare that there is no conflict of interest that could be perceived as prejudicing the impartiality of the research reported.

\section{Funding}

The research was funded by a PRELUDIUM 12 grant from the Polish National Centre for Science (2016/23/N/NZ5/02573)

\section{Author contribution statement}

A K, E S P and M R performed study design, A K and E S P performed data acquisition and interpretation, A K performed statistical analysis, A K and D F prepared the manuscript and E S P and M R performed final revision of the manuscript.

\section{References}

1 Szczepanek-Parulska E, Hernik A \& Ruchala M. Anemia in thyroid diseases. Polish Archives of Internal Medicine 2017127 352-360. (https://doi.org/10.20452/pamw.3985)

2 Wopereis DM, Du Puy RS, van Heemst D, Walsh JP, Bremner A, Bakker SJL, Bauer DC, Cappola AR, Ceresini G, Degryse J, et al. The relation between thyroid function and anemia: a pooled analysis of individual participant data. Journal of Clinical Endocrinology and Metabolism 2018103 3658-3667. (https://doi.org/10.1210/jc.201800481)

3 M'Rabet-Bensalah K, Aubert CE, Coslovsky M, Collet TH, Baumgartner C, den Elzen WP, Luben R, Angelillo-Scherrer A, Aujesky D, Khaw KT, et al. Thyroid dysfunction and anaemia in a large population-based study. Clinical Endocrinology 201684 627-631. (https://doi.org/10.1111/cen.12994)

4 Omar S, Hadj Taeib S, Kanoun F, Hammami MB, Kamoun S, Ben Romdhane N, Feki M, Slimane H \& Kaabachi N. Erythrocyte abnormalities in thyroid dysfunction. Tunisie Medicale $2010 \mathbf{8 8}$ $783-788$.

5 Ford HC \& Carter JM. The haematology of hyperthyroidism: abnormalities of erythrocytes, leucocytes, thrombocytes and haemostasis. Postgraduate Medical Journal 198864 735-742. (https:// doi.org/10.1136/pgmj.64.756.735)

6 Jafarzadeh A, Poorgholami M, Izadi N, Nemati M \& Rezayati M. Immunological and hematological changes in patients with hyperthyroidism or hypothyroidism. Clinical and Investigative Medicine 201033 E271-E279. (https://doi.org/10.25011/cim. v33i5.14352)

7 Lippi G, Montagnana M, Salvagno GL \& Guidi GC. Should women with abnormal serum thyroid stimulating hormone undergo screening for anemia? Archives of Pathology and Laboratory Medicine 2008132 321-322. (https://doi.org/10.1043/15432165(2008)132[321:SWWAST]2.0.CO;2)

8 Gianoukakis AG, Leigh MJ, Richards P, Christenson PD, Hakimian A, Fu P, Niihara Y \& Smith TJ. Characterization of the anaemia associated with Graves' disease. Clinical Endocrinology 200970 781-787. (https://doi.org/10.1111/j.1365-2265.2008.03382.x)
9 Rishi G, Wallace DF \& Subramaniam VN. Hepcidin: regulation of the master iron regulator. Bioscience Reports 2015 35. (https://doi. org/10.1042/BSR20150014)

10 Hernik A, Szczepanek-Parulska E, Filipowicz D, Czarnywojtek A, Wrotkowska E, Kramer L, Urbanovych A \& Ruchala M. Hepcidin and iron homeostasis in patients with subacute thyroiditis and healthy subjects. Mediators of Inflammation 20192019 5764061. (https://doi. org/10.1155/2019/5764061)

11 Hernik A, Szczepanek-Parulska E, Filipowicz D, Abdolall A, Borowczyk M, Wrotkowska E, Czarnywojtek A, Krasinski Z \& Ruchala M. The hepcidin concentration decreases in hypothyroid patients with Hashimoto's thyroiditis following restoration of euthyroidism. Scientific Reports 20199 16222. (https://doi. org/10.1038/s41598-019-52715-3)

12 Fischli S, von Wyl V, Trummler M, Konrad D, Wueest S, Ruefer A, Heering K, Streuli R, Steuer C, Bernasconi L, et al. Iron metabolism in patients with Graves' hyperthyroidism. Clinical Endocrinology 2017 87 609-616. (https://doi.org/10.1111/cen.13450)

13 Lehtihet M, Bonde Y, Beckman L, Berinder K, Hoybye C, Rudling M, Sloan JH, Konrad RJ \& Angelin B. Circulating hepcidin-25 is reduced by endogenous estrogen in humans. PLOS ONE 201611 e0148802. (https://doi.org/10.1371/journal.pone.0148802)

14 Sangkhae V \& Nemeth E. Regulation of the iron homeostatic hormone hepcidin. Advances in Nutrition 20178 126-136. (https:// doi.org/10.3945/an.116.013961)

15 Wang RH, Li C, Xu X, Zheng Y, Xiao C, Zerfas P, Cooperman S, Eckhaus M, Rouault T, Mishra L, et al. A role of SMAD4 in iron metabolism through the positive regulation of hepcidin expression. Cell Metabolism 20052 399-409. (https://doi.org/10.1016/j. cmet.2005.10.010)

16 Radosz A \& Obuchowicz A. The role of hepcidin in regulating iron homeostasis in selected diseases. Developmental Period Medicine 2019 23 137-141.

17 Ruchala P \& Nemeth E. The pathophysiology and pharmacology of hepcidin. Trends in Pharmacological Sciences 201435 155-161. (https://doi.org/10.1016/j.tips.2014.01.004)

18 Fung E \& Nemeth E. Manipulation of the hepcidin pathway for therapeutic purposes. Haematologica 201398 1667-1676. (https:// doi.org/10.3324/haematol.2013.084624)

19 Siddiqi A, Monson JP, Wood DF, Besser GM \& Burrin JM. Serum cytokines in thyrotoxicosis. Journal of Clinical Endocrinology and Metabolism 199984 435-439. (https://doi.org/10.1210/ jcem.84.2.5436)

20 Bossowski A \& Urban M. Serum levels of cytokines in children and adolescents with Graves' disease and non-toxic nodular goiter. Journal of Pediatric Endocrinology and Metabolism 200114 741-747. (https://doi.org/10.1515/jpem.2001.14.6.741)

21 Imani D, Rezaei R, Razi B, Alizadeh S \& Mahmoudi M. Association between IL6-174 G/C polymorphism and Graves' disease: a systematic review and meta-analysis. Acta Medica Iranica 201755 665-671.

22 Mikos H, Mikos M, Rabska-Pietrzak B \& Niedziela M. The clinical role of serum concentrations of selected cytokines: il-1beta, TNF-alpha and IL- 6 in diagnosis of autoimmune thyroid disease (AITD) in children. Autoimmunity 201447 466-472. (https://doi.org/10.3109/0 8916934.2014.914175)

23 Floriani C, Feller M, Aubert CE, M'Rabet-Bensalah K, Collet TH, den Elzen WPJ, Bauer DC, Angelillo-Scherrer A, Aujesky D \& Rodondi N. Thyroid dysfunction and anemia: a prospective cohort study and a systematic review. Thyroid 201828 575-582. (https://doi. org/10.1089/thy.2017.0480)

24 Butterfield AM, Luan P, Witcher DR, Manetta J, Murphy AT, Wroblewski VJ \& Konrad RJ. A dual-monoclonal sandwich ELISA specific for hepcidin-25. Clinical Chemistry 201056 1725-1732. (https://doi.org/10.1373/clinchem.2010.151522)

25 Kubota K, Tamura J, Kurabayashi H, Shirakura T \& Kobayashi I. Evaluation of increased serum ferritin levels in patients with

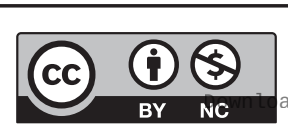

This work is licensed under a Creative Commons Attribution-NonCommercial 4.0 International License. ded from Bioscientifica com at 04/26/2023 01:24:30PM 
hyperthyroidism. Clinical Investigator 199372 26-29. (https://doi. org/10.1007/bf00231112)

26 Czarnywojtek A, Sawicka-Gutaj N, Miechowicz I, Borowska M, Wolinski K, Plazinska MT, Zybek-Kocik A, Straburzynska-Migaj E, Zgorzalewicz-Stachowiak M, Hernik A, et al. Red cell distribution width - a new marker for exacerbation of heart failure in patients with hypothyroidism following radioiodine therapy. Endokrynologia Polska 201869 235-240. (https://doi.org/10.5603/EP.a2018.0018)

27 Aktas G, Sit M, Dikbas O, Tekce BK, Savli H, Tekce H \& Alcelik A. Could red cell distribution width be a marker in Hashimoto's thyroiditis? Experimental and Clinical Endocrinology and Diabetes 2014 122 572-574. (https://doi.org/10.1055/s-0034-1383564)

28 Das KC, Mukherjee M, Sarkar TK, Dash RJ \& Rastogi GK. Erythropoiesis and erythropoietin in hypo- and hyperthyroidism. Journal of Clinical Endocrinology and Metabolism 197540 211-220. (https://doi.org/10.1210/jcem-40-2-211)

29 Snyder LM \& Reddy WJ. Mechanism of action of thyroid hormones on erythrocyte 2,3-diphosphoglyceric acid synthesis. Journal of Clinical Investigation 197049 1993-1998. (https://doi.org/10.1172/JCI106419)
30 Asl SZ, Brojeni NK, Ghasemi A, Faraji F, Hedayati M \& Azizi F. Alterations in osmotic fragility of the red blood cells in hypo- and hyperthyroid patients. Journal of Endocrinological Investigation 2009 32 28-32. (https://doi.org/10.1007/BF03345674)

31 Czarnywojtek A, Owecki M, Zgorzalewicz-Stachowiak M, Wolinski K, Szczepanek-Parulska E, Budny B, Florek E, Waligorska-Stachura J, Miechowicz I, Baczyk M, et al. The role of serum C-reactive protein measured by high-sensitive method in thyroid disease. Archivum Immunologiae et Therapiae Experimentalis 201462 501-509. (https:// doi.org/10.1007/s00005-014-0282-1)

32 Yang Q, Jian J, Katz S, Abramson SB \& Huang X. 17 $\beta$-Estradiol inhibits iron hormone hepcidin through an estrogen responsive element half-site. Endocrinology 2012153 3170-3178. (https://doi. org/10.1210/en.2011-2045)

33 Galesloot TE, Vermeulen SH, Geurts-Moespot AJ, Klaver SM, Kroot JJ, van Tienoven D, Wetzels JF, Kiemeney LA, Sweep FC, den Heijer M, et al. Serum hepcidin: reference ranges and biochemical correlates in the general population. Blood $2011 \mathbf{1 1 7}$ e218-e225. (https://doi. org/10.1182/blood-2011-02-337907)

Received in final form 13 January 2020

Accepted 18 February 2020

Accepted Manuscript published online 18 February 2020
This work is licensed under a Creative Commons Attribution-NonCommercial 4.0 International License. ded from Bioscientifica.com at 04/26/2023 01:24:30PM 